\title{
Indicadores de la gestión pública municipal en turismo sobre temas de accesibilidad y discapacidad
}

\author{
Indicators of municipal public management in tourism on issues of \\ accessibility and disability issues
}

\section{Resumen}

En este trabajo se planteará un aporte al debate en materia de turismo y discapacidad, a partir del diseño de indicadores de accesibilidad turística municipal, como una herramienta de valoración interna de la gestión pública que estimule modelos de sostenibilidad para el desarrollo local, y de complementariedad para la valoración de la calidad turística en el turismo accesible ${ }^{1}$. Este se desplegará en el corredor "Sierras Termas y Lagunas", localizado al sudoeste de la provincia de Buenos Aires, Argentina. Es un corredor configurado por un acuerdo formal entre las localidades de Puan, Tornquist, Guaminí, Adolfo Alsina y Villarino².

El abordaje pretenderá profundizar sobre las diferentes cuestiones complejas de factores coyunturales, ideológicos, de interés sectorial o de miopía estratégica ${ }^{3}$ que se interrelacionan en la gestión pública en materia de accesibilidad turística ${ }^{4}$. Se busca constituir una herramienta de gestión consecuente de políticas públicas articuladas entre diferentes áreas internas de la estructura organizativa municipal, con interrelación jurisdiccional (provincia-nación) y de actores comunitarios.

\section{Palabras clave}

Diseño universal, accesibilidad turística, indicadores de accesibilidad turística municipal.

\begin{abstract}
In this work, a contribution will be made to the debate on tourism and disability, based on the design of municipal tourism accessibility indicators, as a tool for internal assessment of public management that stimulates models of sustainability for local development, and of complementarity for the assessment of the quality of tourism in accessible tourism. This will be deployed in the corridor "Sierras Termas y Lagunas", located to the southwest of the province of Buenos Aires, Argentina. It is a corridor configured by a formal agreement between the towns of Puan, Tornquist, Guaminí, Adolfo Alsina and Villarino.

The approach will seek to deepen on the different complex issues of factors of circumstantial, ideological, sectorial interest or strategic myopia that are interrelated in public management in terms of tourism accessibility. The aim is to constitute a tool of consistent management of public policies articulated between different internal areas of the municipal organizational structure, with jurisdictional interrelation (province-nation) and community actors.
\end{abstract}

\section{Keywords}

Universal design, tourist accessibility, indicators of municipal tourist accessibility.

\footnotetext{
1. Turismo accesible: la Ley de la Nación Argentina $N^{\circ} 25.646$, define al turismo accesible en su artículo 1 de la siguiente manera: "El turismo accesible es complejo de actividades originadas durante el tiempo libre, orientado al turismo y la recreación, que posibilitan la plena integración -desde la óptica funcional y psicológica- de las personas con movilidad y/o comunicación reducidas, obteniendo durante las mismas la satisfacción".

2. En el corredor "Sierra, termas y lagunas" convergen diferentes paisajes de ecléctica geomorfología que configuran interés turístico por su gran variedad cultural y natural.

3. Miopía estratégica: es una construcción conceptual a partir de la definición de T. Levitt, que desarrolla la miopía en el marketing, como una consecuencia del error de la administración para detectar el alcance del negocio, al no reconocer la percepción de los beneficios de la adquisición de un producto o servicio por parte del cliente.

4. Accesibilidad turística: es comprendida como las características específicas de un entorno, producto o servicio que se configura a partir de su adaptación posible y en relación a las necesidades de personas con alguna discapacidad para elegir en igualdad de oportunidad.
}

María Claudia Mazza

<mazzacm@gmail.com>

Universidad Nacional de Quilmes. Argentina

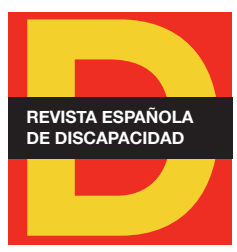

Para citar:

Mazza, M. C. (2019): "Indicadores de la gestión pública municipal en turismo sobre temas de accesibilidad y discapacidad".

Revista Española de Discapacidad, 7 (I): 173-197.

Doi: <https://doi.org/10.5569/23405104.07.01.09>

Fecha de recepción: 19-03-2018 Fecha de aceptación: 10-04-2019 


\section{Introducción}

En las últimas décadas, se observa una transformación paradigmática productiva mundial, en la que se constituye un nuevo tratamiento del territorio y de la ciudad, como soporte material de la actividad humana y de los procesos sociales (Galafassi, 2016). Esta relación conduce a una profunda modificación de la estructura espacial urbana, en la que se persigue un modelo de 'legitimidad' a partir de los recursos que las contienen.

Los gobiernos locales demandan la instrumentación de herramientas que les promuevan un análisis interno de la actuación pública, que contribuyan en la convalidación de sus acciones. Estos cambios provocan una nueva articulación y flexibilidad en la organización institucional pública y privada como desafío de modernización. Las administraciones públicas locales deberán constituir un marco estratégico innovador que acompañe los cambios y necesidades antrópicas de cada territorio, mientras que la agenda gubernamental deberá dar respuesta a las necesidades de la realidad social, a partir del desarrollo de las políticas públicas en concordancia a esa situación.

Los Objetivos de Desarrollo Sostenible (ODS) ${ }^{5}$, planteados por la Organización de Naciones Unidas a todos los países del mundo, han sido configurados a partir de los desafíos que vislumbra la humanidad, con el objetivo de garantizar la misma oportunidad para todas las personas sin comprometer nuestro planeta. Si bien son amplias las líneas temáticas que contemplan los 17 objetivos planteados por el organismo en el 2005 en su Agenda del Desarrollo Sostenible para el 2030, en esta investigación se propuso trabajar, como variable de desarrollo, la actividad turística. La misma se podría configurar como una unidad de análisis de variables complejas en la que son numerosos los ejes temáticos que se deberían abordar para su concepción integral y en atención a la sostenibilidad social, económica, ambiental. A los efectos de nuestro propósito, se focalizará este aporte, proponiendo un modelo metodológico de valoración de la gestión municipal y de calidad turística. Puntualizando en la accesibilidad turística, en referencia a la perspectiva de la discapacidad. Así mismo, se observa que la "perspectiva discapacidad" es visiblemente constitutiva de la gran mayoría de los ODS.

Con este aporte se estaría configurando una herramienta de diagnóstico posible, de bajo coste, intuitiva y de fácil aplicación intersectorial gubernamental, en la que se puedan observar de manera transversal aquellas cuestiones susceptibles de modificar y que también podría ser utilizada en el abordaje interjurisdiccional.

Romero (2011), analizando el hábitat de su proximidad en su relación con el desarrollo territorial y el paisaje pero con una posible lógica comparativa al tema que nos ocupa, entiende que las competencias relacionadas con el ordenamiento territorial, se encuentran establecidas por parlamentos y gobiernos autónomos. Pero que también, el Estado -Nación- tiene una gran instrumentación y capacidad para establecer políticas de gran impacto territorial. En razón a ello advierte la necesidad de uso de dispositivos de coordinación y cooperación institucional vertical y horizontal entre esferas de gobierno. Parte de una actuación de políticas públicas, impregnadas de una relación de equidad entre las personas, sobre un enfoque integrado por sobre los sectoriales. Así mismo, puntualiza sobre los cimientos de un buen gobierno gobernanza democrática y territorial.

5. Objetivos de Desarrollo Sostenible (en línea): <https://www.un.org/sustainabledevelopment/es/sustainable-development-goals/>, acceso 10 de abril de 2019. 
En esta sintonía, la implementación de políticas públicas articuladas entre áreas y jurisdicción como parte de la gestión estatal en materia de turismo-discapacidad, requiere de una configuración puntualizada en las necesidades de accesibilidad del conjunto de la población heterogénea universal ${ }^{6}$.

Si bien en los últimos años las investigaciones sobre temas como la discapacidad se han establecido con mayor frecuencia, no han alcanzado aún la posibilidad de representar la realidad particular junto a las necesidades del grupo social representado por las personas con algún tipo de discapacidad. La formulación de estadísticas o registros es también una de las consonancias para la investigación y representación del conjunto social, dado que son la resultante de una nula periodicidad, como así también una incongruencia para establecer sistematizaciones y comparativas. Con mayor rareza se observan escasos trabajos en los que se estimule un abordaje interdisciplinario de la evaluación de la gestión municipal en relación a la actividad turística inclusiva, focalizando la multiplicidad de factores, tanto internos como externos, articulados a la jurisdicción local.

La interpretación de la discapacidad es un concepto considerado como el consecuente de una evolución social, que puntualiza sobre dos cuestiones o paradigmas bien diferenciados. Por un lado, todas aquellas características que presenta una persona con discapacidad en materia de salud y su rehabilitación. Y por otra parte, aquellas acciones sociales que estimulan o no su participación en la sociedad. En el primer caso, estaríamos especificando su déficit y, consecuentemente, afirmando aquellas cuestiones o actividades que no podrían llevarse a cabo, por no tener esta capacidad-habilidad para su resolución.

Esta es una determinación a partir de prototipos o estereotipos promovidos como "normales" del ser humano. El concepto de normalidad-anormalidad ha sido introducido en diferentes disciplinas analíticas a partir de los criterios estadísticos desarrollados por Carlos Federico Gauss (1777-1855). Sobre esta realidad conceptual, que está reconsiderándose socialmente en los últimos tiempos, se ha postulado como "hombre normal" al que se asemeja o acerca a la media aritmética del grupo analizado. Sobre esa "deformación conceptual" se han venido desplegando diseños de diferentes modelos de ropa, ámbitos de recreación, accesorios, asientos, como para enunciar algunos ejemplos que son promovidos con la lógica de la "mayoría". Así mismo, también hace presuponer una configuración circunscripta a leyes de mercado en el que prima una ecuación económica que favorece principalmente a la rentabilidad.

El segundo caso será el eje esencial en el que centraremos nuestras acciones para lograr la incorporación en las diferentes actividades sociales a este colectivo, proponiendo un espacio de interacción, con igualdad de oportunidades y derecho. Por ejemplo, una actividad deportiva como el esquí, es susceptible de llevarla a cabo una persona con discapacidad motriz a partir de la adaptación que el entorno-sociedad le plantee; incorporando elementos que cumplan con la función supliendo su déficit y así lograr autodeterminación ${ }^{7}$ y autonomía ${ }^{8}$ en dicha actividad.

\footnotetext{
6. Población heterogénea universal: comprende al conjunto de la población, sin realizar distinción o categorías analíticas. Nos referiremos al colectivo o conjunto social como sinónimos, cuando se puntualiza en un grupo de personas que tienen algún déficit particular que requieren de una adaptación para su plena interacción y participación en la sociedad. En este último recorte involucramos a las personas con alguna discapacidad, dado a que se entiende que existen algunas especificidades de su déficit que necesitan ser abordadas en su singularidad para poder comprender su totalidad. Esta autora reconoce que, en la actualidad, aún es necesario trabajar algunas cuestiones de la discapacidad sin perder el foco de sus características particulares. Promover el conocimiento más concreto de las necesidades de este colectivo probablemente estimule el andamiaje necesario para evolucionar a un constructo social más inclusivo.

7. Autodeterminación: es la capacidad de una persona para poder decidir, elegir sin condicionamientos, sobre qué se quiere o determina hacer. 8. Autonomía: es la capacidad de una persona para desarrollar por sí sola o con independencia a partir de sus habilidades.
} 
Por otra parte, se podría calificar el déficit o la necesidad de accesibilidad según el tiempo que perdura esa situación, tal como se puede observar en el cuadro 1. Así mismo, es de considerar que tanto en la aplicación del diseño universal en los servicios como en los diferentes objetos de un territorio, se establecen diferentes nociones de practicidad que estimulan la aplicación de "ajustes razonables" para alcanzar la autonomía y autodeterminación de las conductas individuales de este colectivo social para la igualdad de oportunidades, en tanto se advierte un beneficio para el resto de la comunidad.

Este tipo de adecuación, tanto en productos como en entornos, a partir de principios del diseño universal, ha sido liderado inicialmente por Ronald L. Mace ${ }^{9}$. Este fue el autor que acuñó dicho concepto. Fundador del Centro para el Diseño Universal (Center for Universal Design) de la Universidad de Carolina del Norte, su aporte ha sido esencial para dar un reconocimiento masivo e interdisciplinario acerca de la necesidad de ampliar una visión reconocida al momento respecto de la accesibilidad. Inicialmente, se focalizaba al acceso en referencia a la discapacidad física, mientras que en la actualidad no solo se integra al colectivo con alguna discapacidad, sino que se presenta un diseño en el que se pueda involucrar un mayor número posible de la sociedad en su conjunto, sin tener que adaptar o realizar diseños específicos. Posteriormente, el autor solicita a un equipo interdisciplinar desarrollar los principios del diseño universal, reflejados en las siguientes categorías:

\section{Principios del diseño universal}

1. Uso equitativo

2. Uso flexible

3. Uso simple e intuitivo

4. Información perceptible

5. Con tolerancia al error

6. Bajo esfuerzo físico

7. Tamaño y espacio para el acceso y uso

En ejercicio al reconocimiento sobre la especificidad de las necesidades singulares a cada discapacidad, es menester proponer algunas líneas de abordaje analizables y valorizables, que determinen el nivel o grado alcanzado en dicho proceso de gestión municipal sobre el tema investigado. Hacer visible cada uno de los déficits probablemente representados en una necesidad, deberían constituir para la gestión, al menos la intencionalidad de alcanzar una adaptación específica para establecer la participación al medio.

\footnotetext{
9. Ronald L. Mace (1941-1998), arquitecto, diseñador, profesor y usuario de silla de ruedas, fue uno de los pioneros en el diseño accesible, participando en la elaboración de la Ley de Americanos con Discapacidad (ADA). En 1989, consiguió fondos federales para crear el Centro de Vivienda Accesible, al que posteriormente se conocería como Centro de Diseño Universal, ubicado en la Escuela de Diseño de la Universidad de Carolina del Norte en Raleigh, y del que sería su primer director. Actualmente es un centro de referencia y de investigación en materia de Diseño para todos, organizando en 1998 la $1^{a}$ Conferencia Internacional en Diseño para Todos, con el lema "Diseñando para el siglo XXl" en Nueva York (en línea) < http://laaccesibilidadesdetodos.blogspot.com.ar/2011/02/los-principios-del-diseno-universal.html>, acceso 15 de abril de 2019.
} 


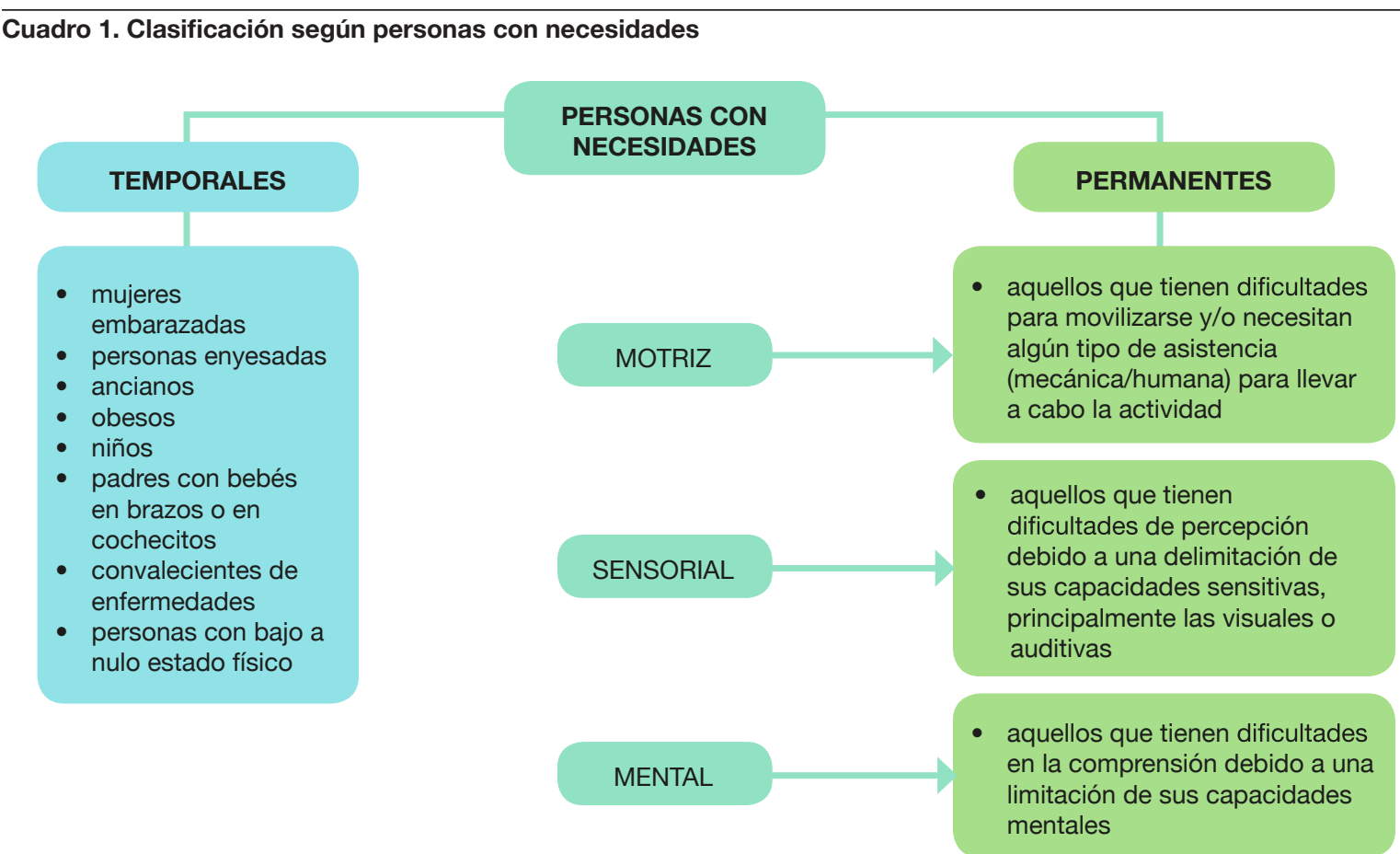

Fuente: elaboración propia, adaptado de las directrices de accesibilidad turísticas del Ministerio de turismo de la Nación y del Plan Nacional de accesibilidad 2004-2011 de la República Argentina.

Si bien es vasta la literatura que da cuenta de una investigación con aplicación de indicadores ambientales, se observa un gran déficit de estadísticas sistemáticas que den una aplicabilidad evaluativa concreta que pueda transparentar procesos de gestión (Sánchez, 2011; OMT, 2000). Esta situación se agudiza si en la evaluación de estos procesos se toma como eje la gestión en su relación con la discapacidad.

Según la Comisión Económica para América Latina y el Caribe -CEPAL- (CEPAL, 2017), existe un amplio respaldo para los derechos de las personas con discapacidad en los marcos normativos en todos los niveles -nacionales, regionales e internacionales-. Si bien las instituciones nacionales, los mecanismos de coordinación intersectorial, la articulación territorial y los mecanismos de participación ciudadana no han sido suficientes para que los derechos, en la práctica sobre estas latitudes, sean eficientes.

En su amplia mayoría, en los países latinoamericanos, las políticas públicas urbanas y rurales inclusivas focalizadas en la discapacidad hacen referencia en la práctica a cuestiones principalmente asistenciales, dejando a la persona con alguna discapacidad, en situación de vulnerabilidad y con la imposibilidad de elegir y de co-construir el territorio que habita ${ }^{10}$ consecuente de sus derechos y en igualdad de oportunidades. Tan

10. La co-construcción del territorio es un concepto que se ha asociado a otro concepto denominado "la municipalización del bien común". Y en este sentido, se observa como un proceso social actual en el que se configuran nuevas demandas y nuevos sujetos, emergentes de una cultura de la acción (Blanco et al., 2016). El habitante de un territorio de manera individual y social constituye el elemento vivo de interacción que junto a otros actores determinan la configuración territorial. 
solo se plantea una actuación homogénea a partir del asistencialismo ${ }^{11}$ que propone una continuidad homogeneizante sobre este colectivo (Núñez y Roze, 2011).

El nuevo modelo de gestión local contempla una participación ciudadana que demanda sus derechos. La transformación de la agenda de las políticas públicas ha estimulado el poder de los municipios sobre la gestión referida a demandas más locales.

Autores como Blanco et al., 2016 afirman que:

"El municipalismo del bien común genera una esfera pública compartida: con presencia institucional y comunitaria, con alianzas y procesos de coproducción. Implica conjugar una dimensión sustantiva de justicia urbana con una dimensión operativa de democracia abierta. Un campo de intersecciones donde la agenda urbana adquiere pulsión comunitaria activadora de ciudadana; donde las prácticas sociales adquieren fuerza universalista constructora de derechos; donde todo ello queda entrelazado" (Blanco et al., 2016: 7).

Así mismo, profesionales como Schelotto ${ }^{12}$ advierten que el ordenamiento territorial está poco integrado en la política pública y en la transformación territorial, y reconoce un amplio potencial en la gestión planificada y sostenible debido a su transversalidad en todos los niveles estatales.

En los últimos años emergieron diferentes "modelos de intervención", planteando lineamientos generales, y en algunos casos particulares, para lograr configurar territorios turísticos accesibles o destinos inteligentes en los que también se benefician sus habitantes. Las normas $\mathrm{UNE}^{13}$ podrían ser algunas muestras de aportes relativos a esta tendencia. $\mathrm{O}$ así también los criterios $\mathrm{DALCO}^{14}$ definidos en la misma norma.

En razón de ello, el desafío se puntualiza en la configuración de herramientas que promuevan esta valoración en dicha relación evaluativa (discapacidad-turismo), representada en la figura 1. Obtener la posibilidad de autoevaluarse en referencia al accionar gubernamental sobre las necesidades de accesibilidad del conjunto poblacional en materia turística contribuirá al conocimiento de la situación en la que se encuentra el territorio en dicho tema y, en consecuencia, a la toma de decisiones más eficientes en el sistema de gestión, independientemente del tamaño del territorio y características particulares de sus habitantes. La puesta en práctica de este proceso evaluativo constituirá un proceso plagado de información analizable y potencialmente transversalizada a otros escenarios de la configuración socio territorial que, a partir de su digitalización, será susceptible de ágiles comparativas, interpretación y verificación.

11. El asistencialismo de las políticas públicas es considerado a partir del accionar vertical gubernamental tradicional que atiende cuestiones referidas a lo inmediato y en su relación con la necesidad primaria. En tanto, no se configuran políticas públicas integrales que atiendan cuestiones complejas, de largo plazo y alcance.

12. Entrevista realizada por la Federación Panamericana de Asociaciones de Arquitectos a Salvador Shelotto (en línea). http://www.fpaa-arquitectos.org/espanol/hacia-territorios-mas-inclusivos-y-sostenibles-22?nid=145, acceso 15 de abril de 2019.

13. Norma UNE 178501 que regula el "Sistema de Gestión de los Destinos Turísticos Inteligentes: Requisitos" y Norma UNE 178502 "Indicadores y herramientas de los destinos turísticos inteligentes" (en línea) <https://www.une.org/encuentra-tu-norma/busca-tu-norma/norma/?c=N0060240>, acceso 20 de marzo de 2019.

14. Criterios DALCO: conjunto de requisitos relativos a las acciones de deambulación, aprehensión, localización y comunicación, que ha de satisfacerse para garantizar la accesibilidad universal. DALCO es el acrónimo de: D. DEAMBULACIÓN; A. APREHENSIÓN; L. LOCALIZACIÓN; CO. COMUNICACIÓN (en línea). <http://www.juntadeandalucia.es/turismocomercioydeporte/opencms/areas/turismo/calidad/calidad-certificados-ydistinciones/glosario/8b2d7530-b381-11e0-a14a-ffbfc467dff6/>, acceso 16 de abril de 2019. 
Figura 1. Valoración de la accesibilidad
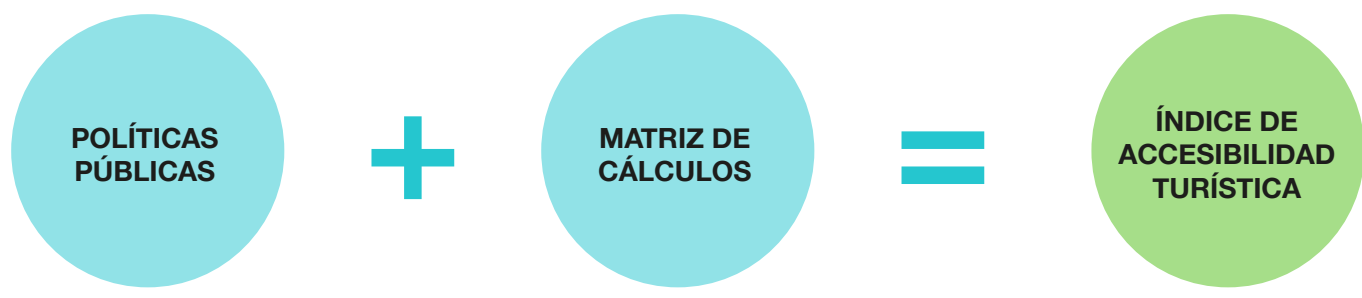

Fuente: elaboración propia.

\section{Marco teórico}

Autores como Gallopin (2006) y Reboratti (2000) han contribuido al ejercicio de una mirada integral del desarrollo sostenible, estimulando un análisis de subsistemas interrelacionados en el que se engloban como dos grandes categorías el subsistema humano y el subsistema ecológico. Sobre esta base se vienen estableciendo metodologías en las que se diseñan indicadores ambientales para el desarrollo sostenible.

En las últimas décadas se ha incorporado en las estrategias para el desarrollo de la actividad en los destinos turísticos, cuestiones relacionadas con: monitoreo, reducción de impactos ambientales, educación para los turistas, pobladores locales, planificación, entre otros (Ivars, 2001; OMT, 1997; Valls, 2004; Sancho et al., 2007; Sánchez, 2011; OMT, PNUMA, 2005). Desde el enfoque de gestión integrada, han evolucionado e incorporado la cuestion ambiental en los organismos públicos, proponiendo diferentes valoraciones.

Subirats (2010) propone lineamientos para lograr repensar la política pública en los nuevos estilos de gobiernos. Plantea la construcción colectiva de intereses generales, junto a la competencia de las distintas esferas de gobierno. Destaca que un gobierno en red desdibuja las fronteras entre las diferentes agencias de gobierno, priorizando la trasversalidad, interdependencia y cooperación en torno a la problemática común.

Cravacuore (2015) afirma que analizar la gestión municipal argentina supone observar un modelo de agotamiento, con recursos propios destinados tan solo a pago de salarios y gastos corrientes, con un derroche de escasos recursos, sin planificación y evaluación de su situación.

En respuesta a este contexto, las organizaciones municipales deberán conciliar modelos participativos de gestión en los que se vislumbren los diferentes actores de interés del territorio, con sus lógicas comportamentales. Así mismo, sobre la base de las facultades concebidas consecuentes de un sufragio, deberán estimular la construcción de escenarios de administración genuina de los bienes públicos en la que se asegure la representatividad del conjunto de los ciudadanos. Para ello se debería promover el desarrollo, conciliando el equilibrio de las tensiones para asegurar la gobernabilidad y el aumento de la calidad de vida de la sociedad. 
También agrega este autor que en este conjunto de modificaciones interdisciplinarias se desencadenan cambios y elecciones relacionadas con la aplicación de modelos o herramientas innovadoras universales en la gestión municipal. Allí se destaca la calidad en el servicio a nivel institucional y su relación con los procesos, resultados y responsabilidades conferidas en cada tarea, desempeño e idoneidad.

En relación a la transformación en ejercicio de los municipios y gobiernos locales, autores como Brugué, J. et al. (1998) observan que, con una mayor o menor intensidad, se establece la revalorización emergente de estos espacios como consecuencia de la globalización y del cambio político de estos gobiernos locales.

Por otra parte, es menester reafirmar también la necesidad de un trabajo con visión sistémica e integral en el abordaje analítico del turismo (Bertalanffy, 1968)). Su enorme complejidad, de acuerdo a las asociaciones interdisciplinarias y articulación e interrelación de sus subsistemas, convierten a esta teoría general de sistemas en una sinergia de multipropósito en el que confluye una misma finalidad. Las diferentes acciones que se deberían desplegar como política pública en dicha materia se relacionan con diferentes áreas de gobierno, que deberían articular su gestión para el cumplimiento de dicho objetivo.

En el figura 2 se proponen algunos ejemplos de áreas de gestión gubernamental, que se deberían asociar en la conformación de una política integral en materia de turismo accesible. Sobre esa interacción de áreas se debería tener como eje trasversal la temática de la accesibilidad-discapacidad. La política pública que debería desprenderse de las áreas que se vinculan a la actividad del ocio y el turismo que allí se manifiestan son también constitutivas de políticas que benefician al conjunto de la población.

\section{Figura 2. Gestión integral articulada del turismo accesible}
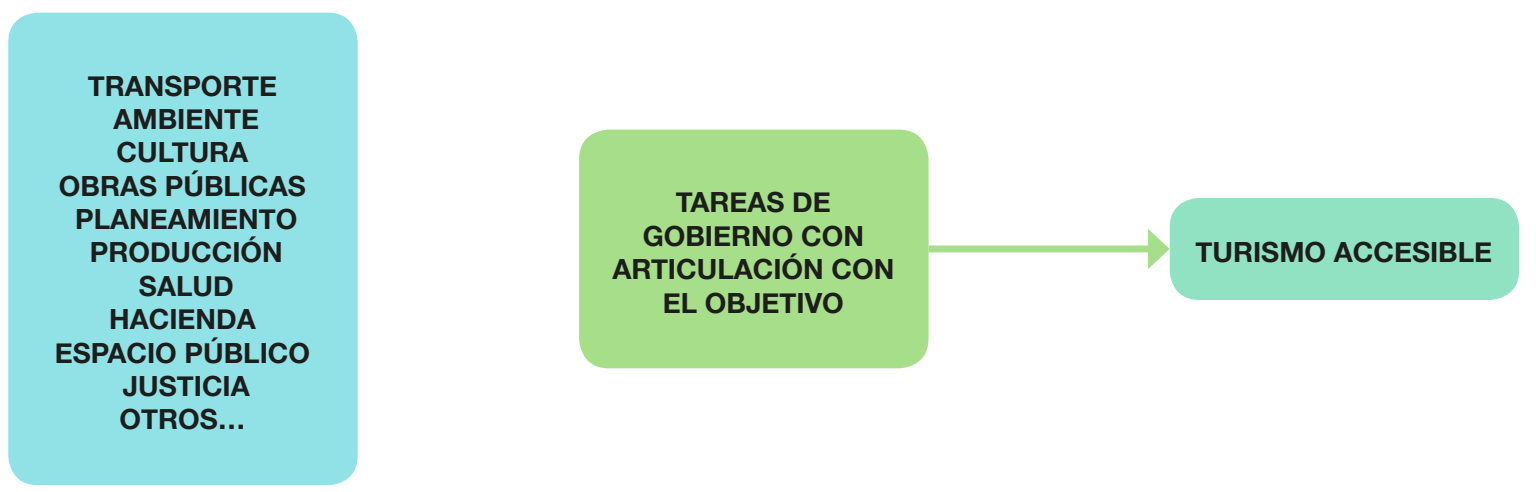

Fuente: elaboración propia.

Así mismo, el emprender un viaje configura una valoración intangible, subjetiva e irrepetible a partir de las vivencias obtenidas durante todo su proceso. Los resultados de esa valoración se alcanzan a partir de la sumatoria de los diferentes elementos que interactúan con el viajero desde el origen al destino del viaje realizado. En el caso de las personas con discapacidad la accesibilidad también es incorporada en la valoración. Todas las fases del proceso del viaje deberán establecerse de manera inclusiva, atendiendo la discapacidad de la persona para obtener la satisfacción plena del viaje o del desarrollo del ocio y la recreación. 
Según el informe de la Organización Mundial de la salud OMS (2011), existen en el mundo más de mil millones de persona con alguna discapacidad. En tanto, de acuerdo a cifras nacionales de la República Argentina elaboradas por el Instituto de Estadísticas y Censo (INDEC), se plantean los siguientes resultados del Censo Nacional de Población, Hogares y Viviendas del año 2010: el 12,9\% que habita en viviendas particulares presenta alguna dificultad o limitación permanente (física o mental). La mayoría de los censados declararon tener una sola dificultad. Dificultad visual: 2.069 .151 , que representan el $60 \%$ de la población total. Dificultad motora (inferior-superior): un poco menos del $24 \%$ de los habitantes. La dificultad auditiva y cognitiva representa el $8 \%$ en cada caso.

Estos resultados representan una porción del mercado (persona con alguna discapacidad) con la potencialidad de realizar actividades de ocio y turismo. También sus familias, en la mayoría de los casos, se encuentran limitadas al condicionamiento de los servicios y equipamiento accesibles para poder emprender un viaje en compañía de la persona que tiene la dificultad o deficiencia (Puga, 2005). Vale decir que se encuentra afectado el núcleo familiar.

Este colectivo social es posible que sean actores del mercado turístico sin restricción alguna a la temporalidad del destino. En los tiempos modernos y de acuerdo a la probable adaptación del espacio laboral, es posible que también logren incorporar durante su productividad, su tiempo de ocio y de turismo.

Así mismo, un turismo responsable debe desarrollar espacios turísticos inclusivos en los que se establezca la igualdad de oportunidades en los diferentes servicios turísticos y no turísticos existentes en el destino. Ello debe acordarse como parte de una política de desarrollo sostenible nacional y de calidad (OMT, 2016).

El turismo accesible corresponde a una actividad sociocultural y económica, como cualquier otra actividad del ser humano, que debería estar enmarcarda en los principios del desarrollo sostenible. De este modo Rifai plantea que:

\footnotetext{
"La accesibilidad es un elemento crucial de toda política de turismo responsable y sostenible. Es una cuestión de derechos humanos y es también una extraordinaria oportunidad de negocio. Por encima de todo, debemos darnos cuenta de que el turismo accesible no solo es bueno para las personas con discapacidad o con necesidades especiales, es bueno para todos" (OMT, 2014: 1).
}

Tanto los convenios internacionales como las declaraciones, leyes y reglamentaciones nacionales han convalidado un desarrollo de la actividad turística para todos. Por ejemplo, la Convención sobre los derechos de las personas con discapacidad, que ha sido contemplada en la actividad turística a partir de su referente, la Ley Nacional $N^{\circ} 25.643$, y que será referenciada en este artículo en párrafos posteriores.

Después de muchos años de labor de la comisión especial de Naciones Unidas, junto a diferentes actores gubernamentales y no gubernamentales, trataron bajo un enfoque holístico e integral una convención con protocolos facultativos para promover y proteger los derechos y la dignidad de las personas con discapacidad. Dos años mas tarde de dicha convención, Argentina convalida como Estado miembro, bajo la configuración de la Ley Nacional $N^{0} 26.378^{15}$. También el aporte del Codigo Etico del Turismo intenta

15. Ley de la Nación Argentina 26.378 "Apruébase la Convención sobre los Derechos de las Personas con Discapacidad y su protocolo facultativo, aprobados mediante resolución de la Asamblea General de las Naciones Unidas del 13 de diciembre de 2006" (en línea). <http://servicios.infoleg. gob.ar/infolegInternet/anexos/140000-144999/141317/norma.htm>, acceso 12 de abril de 2019. 
establecer de manera voluntaria, algunos lineamientos en referencia a los derechos y respeto de este colectivo (OMT, 1999).

En este contexto, ha surgido la Ley Nacional Argentina № 24314 con su decreto reglamentario 914/97, que representan el marco normativo en plena diversidad, enmarcando sus servicios de acuerdo a criterios universales. Así también, la Nacional № 25643 de Turismo Accesible define en su artículo 1: "El turismo accesible es complejo de actividades originadas durante el tiempo libre, orientado al turismo y la recreación, que posibilitan la plena integración -desde la óptica funcional y psicológica- de las personas con movilidad y/o comunicación reducidas, obteniendo durante las mismas la satisfacción" (Mazza, 2018).

Con este marco legal, el desafío socio gubernamental debería estar centrado en la construcción de un modelo territorial que estimule la igualdad de derecho. Y para ello, los gobiernos deberán acompañar subsanando las desigualdades y transformando las necesidades de sus habitantes, a partir de políticas integrales e inclusivas que estimulen el bienestar. Probablemente, los esfuerzos de la gestión pública deberían circunscribirse a acciones enmarcadas en políticas públicas incluyentes, cumplimentando con un diseño para todos o diseño universal. Y en relación a este término, la Comisión Nacional Asesora para la integación de personas discapacitadas (CONADIS) oportunamente lo ha definido como aquella actividad humana que concibe, proyecta y construye el entorno físico, de manera tal que ninguna persona, sea cual sea su condición, quede excluida de su uso y disfrute.

Por otra parte, se observa que el desarrollo de políticas públicas consecuente con la universalización social desencadena un sin número de beneficios inclusivos de las diferentes actividades sociales locales, tanto para los visitantes como para las personas que habitan ese territorio y tienen o no algún tipo de déficit. Este acto por lo general, es bien recibido por la comunidad local en su conjunto, de acuerdo al reconocimiento de acciones que igualen oportunidades.

En la figura 3, se plantea una instancia de alternativas observables y medibles en la que se configuran las probables causas por las que se presume la falta o no de accesibilidad turística, evaluadas en las diferentes fases de abordaje informativo.

Es conveniente aclarar que si bien el término "accesibilidad turística" evoca a diferentes posibilidades o aspectos que pueden ser considerados en un destino turístico en referencia a la accesibilidad, el objeto de nuestro estudio se puntualiza en la accesibilidad en relación con la discapacidad, como una dimensión social en la que se involucran cuestiones: culturales, políticas, de interrelación social, institucional, demográfica (Gallopin, 2006). 


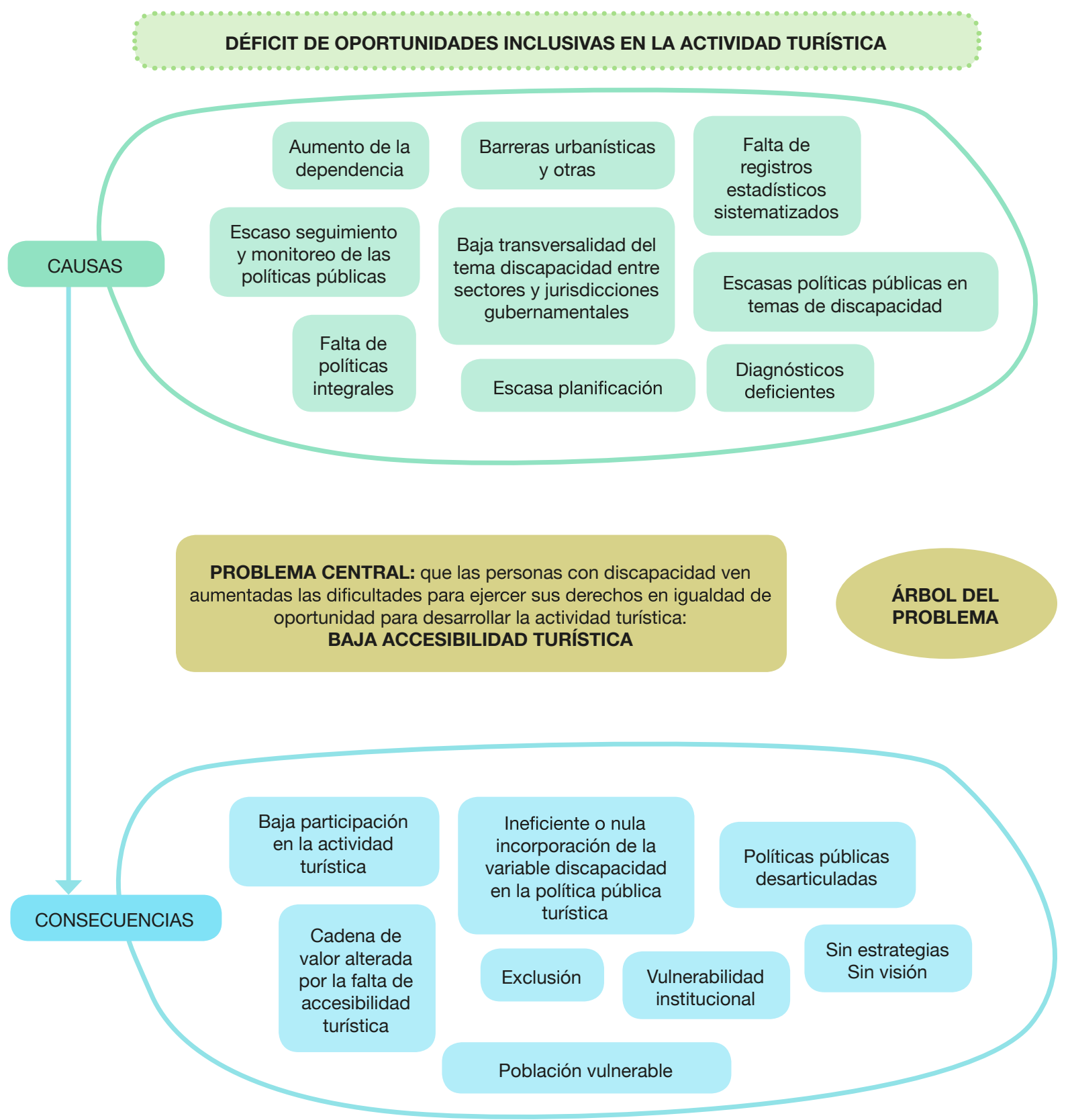




\section{Metodología de abordaje}

A partir del contexto planteado, se observa en materia de turismo y recreación la necesidad de establecer una serie de indicadores evaluativos de la gestión municipal en materia de accesibilidad turística. Establecer una herramienta para medir la representación de las acciones gubernamentales y la instancia de articulación de las políticas públicas beneficiará a las instituciones para lograr tomar conocimiento respecto de la situación real y comparativa entre municipios, para construir, a posteriori, una gestión más acorde a las necesidades planteadas en la comunidad sobre la base del tema investigado. En definitiva, la complejidad de la actividad del ocio y el turismo accesible requiere de un análisis sistémico e integral en el que se constituyan la mayor cantidad de elementos-componentes analizables que interfieren en la actividad turística, para alcanzar una mejor construcción de esa realidad sistémica, y así gestionar una política pública más eficiente.

Así mismo, se estima que no todos los municipios logran obtener un mismo nivel de desarrollo en las políticas públicas sobre el tema en cuestión, y por ello se observa la necesidad de dividir en dos niveles la recolección e interpretación de la información.

Se constituye una primera instancia en la que se deberá evaluar el "qué" de la gestión municipal. Se persigue un primer nivel de datos en el que agentes gubernamentales-comunidad local-turista responderán sobre lo que se hace o se percibe que se hace en la gestión, en materia de accesibilidad turística. Y para ello, el inicio de recolección de datos analizables tendrá una jerarquía general en la que se busca indagar sobre aquellos primeros pasos de la política pública en su relación con la discapacidad y el turismo; su nivel de articulación entre las diferentes áreas gubernamentales; su correlación con la jurisdicción nacional y en relación a la calidad. Esta primera instancia será la que abordaremos en la presentación de este artículo y que ha sido reflejada en la Figura 4.

Tras los resultados obtenidos en ese primer abordaje, es menester tomar conocimiento con un grado de mayor profundización respecto de la gestión. Allí se intentará reconocer de la gestión, el "cómo" se lleva a cabo esa intervención. En razón a ello, se indagará sobre la base de indicadores del primer nivel, pero con una mayor disgregación, en la que podamos reconocer lo que "se hace" y "cómo se hace". Vale decir que se investigará sobre la instrumentación de esas intervenciones y el impacto sobre los beneficiarios.

Para obtener los datos de la primera valoración, el "qué" de la gestión, se ha seleccionado el cuestionario. Dado que son temas que aún podrían obtener disímiles interpretaciones conceptuales en su resolución, se ha escogido como metodología de valoración un diseño de cuestionario con diez preguntas de respuestas cerradas que logren, bajo un mismo criterio, un ágil análisis de información general y básica de lo requerido. En el caso del corredor turístico elegido, observamos que se encuentra incursionando en temas aún poco experimentados in situ, con nula sistematización de algún tipo de estadísticas referidas a temas relacionados con la actividad turística y la discapacidad, a excepción del sector privado en la categoría de alojamientos, que ha resuelto voluntariamente especificar en revisiones realizadas por la gestión pública, algún tipo de información referida a las adaptaciones en sus alojamientos.

Los resultados que se obtengan podrán ser construidos cuantitativa y cualitativamente, lo que hace más enriquecedor el análisis para su evaluación y comparación. También serán susceptibles de ponderación la 
Figura 4. Metodología de construcción de indicadores de gestión municipal sobre la accesibilidad turística en su relación con la discapacidad

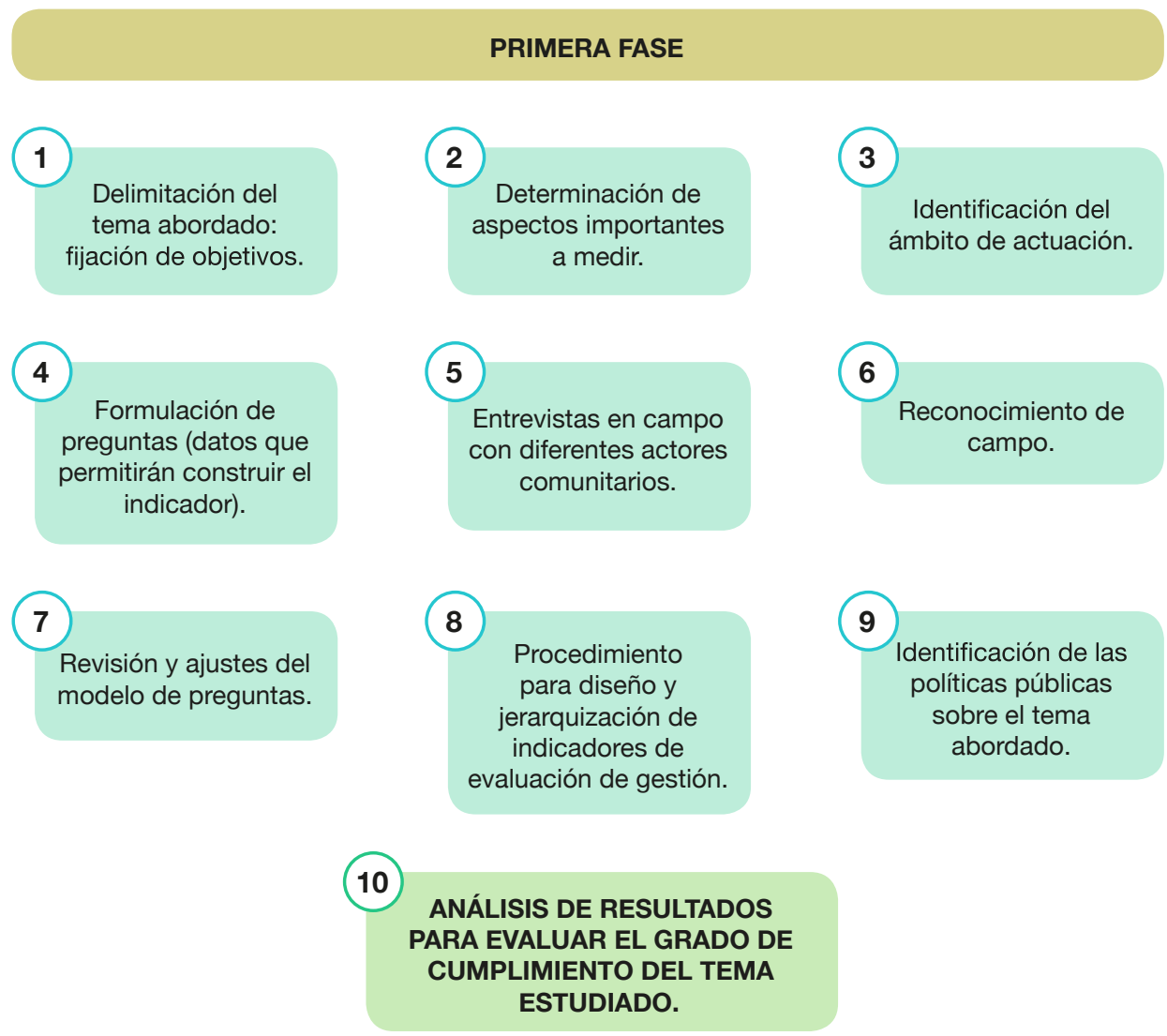

Fuente: elaboración propia.

determinación de una frecuencia en la toma de los mismos para lograr una continuidad evolutiva y una mayor capacidad analítica.

Este cuestionario se ha diseñado inicialmente antes del trabajo de campo y tomando en consideración las necesidades básicas de este colectivo social, centrándose en los déficits generales que cada discapacidad contiene. Se ha focalizado sobre aquellas necesidades-demandas "especiales y o específicas" abordadas en las Recomendaciones de la OMT por un turismo accesible para todos; el diseño universal; y de acuerdo al auto reconocimiento del investigador, a partir de la visita al territorio turístico. Este análisis previo ha contribuido a interpretar en campo aquellas cuestiones visiblemente observables, como por ejemplo: la accesibilidad -física, comunicacional-en las terminales de ómnibus de larga distancia; o a partir de la navegación en los sitios webs oficiales.

En este caso, como en otros, el déficit de infraestructura y su adaptación, promovida como consecuencia de acciones gubernamentales, se constituyen como "indispensables" para poder llevar a cabo la actividad turística para este colectivo. 
Posteriormente, se realizaron los ajustes pertinentes en el cuestionario de acuerdo a las diferentes observaciones desarrolladas en el territorio durante la primera visita, así como a partir del aporte de información proporcionada en las diferentes entrevistas informales semiestructuradas realizadas a algunos habitantes locales con vinculación directa o no con la actividad turística, como por ejemplo: personal de restaurantes, personas en plazas, negocios de productos variados, ubicados en sitios céntricos, entre otros. Pero también se ha trabajado sobre la base informativa adquirida de las diferentes entrevistas realizadas a los agentes gubernamentales de diferentes áreas de la gestión del corredor turístico, durante la visita al territorio. El objetivo de estas entrevistas estaba circunscripto a recabar información relevante para profundizar sobre temas referidos a la discapacidad y accesibilidad turística para contribuir en el enriquecimiento del diseño del cuestionario previamente realizado.

\section{Cuadro 2. Cuestionario de evaluación de la gestión en la accesibilidad turística}

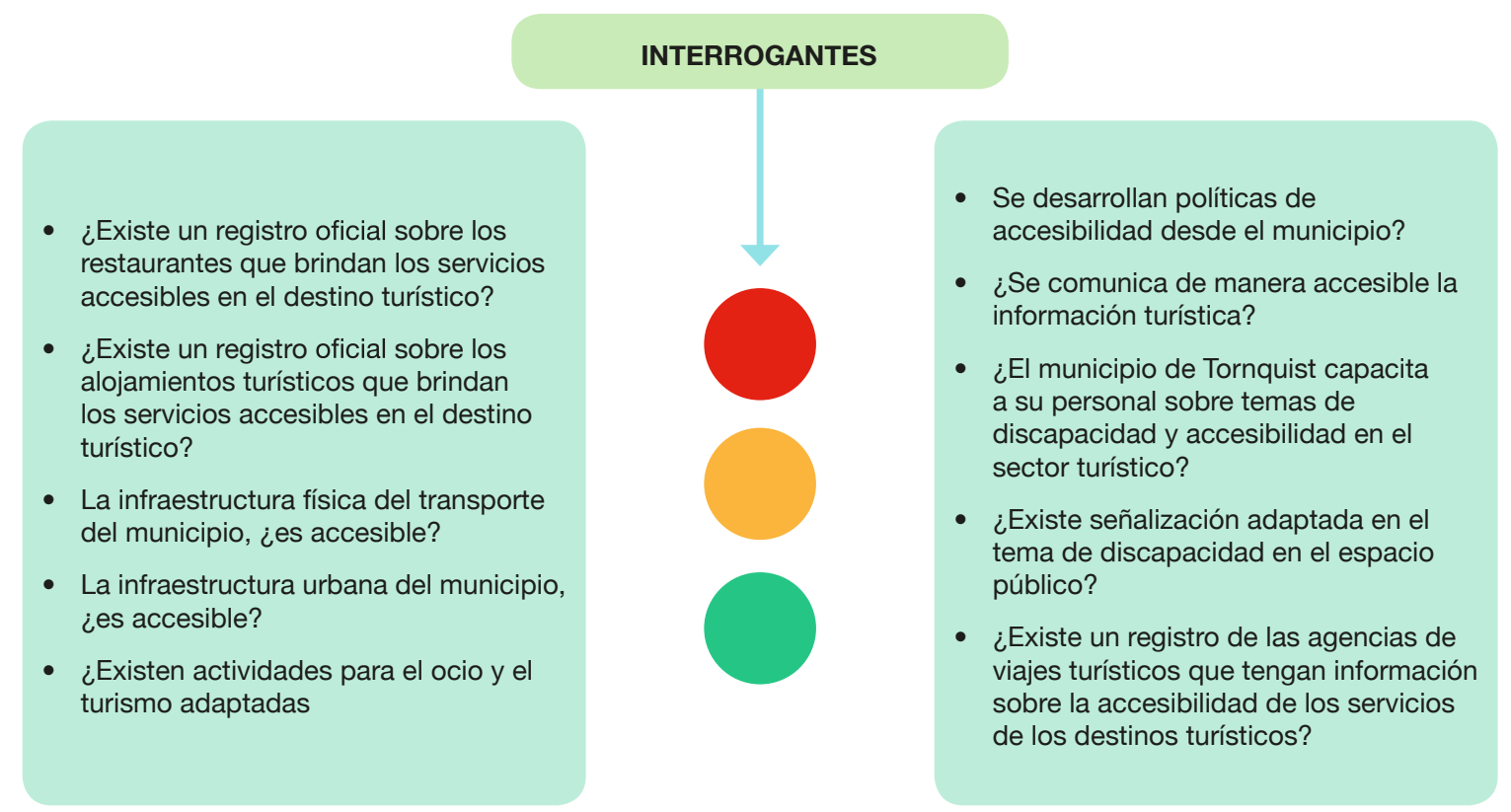

Fuente: elaboración propia.

El cuestionario presentado en el Cuadro 2 pregunta sobre temas relacionados con el despliegue de políticas públicas referidas a: consideraciones urbanísticas, de ordenamiento territorial de servicios y equipamientos turísticos y no turísticos, entre otras cuestiones relevantes para la actividad turística en su relación con la accesibilidad turística en igualdad de oportunidades. En el primer ciclo de recolección de datos se tiene el propósito de que los diferentes actores valorativos -comunidad local-visitante-agente gubernamental-, respondan respecto a las intervenciones públicas que se realizan en el municipio en materia de accesibilidad turística y discapacidad. Tener conocimiento y/o percepción de estas cuestiones por parte de estos actores reflejará la situación o realidad en la materia y con estos resultados se podría inferir, en una primera instancia, lo que se está realizando en la gestión y cómo se percibe. 
En esta etapa es indispensable que los gestores gubernamentales que se encuentran involucrados en alguna intervención referida a estos temas respondan al cuestionario pues es de una gran relevancia para este momento de la investigación contar con respuestas de la comunidad local. Estas podrían aportar datos principalmente sobre la discapacidad y las necesidades que visibilizan en el territorio en este tema. Por ello se ha determinado arbitrariamente una muestra no probabilística de sujetos disponibles sobre grupo etario mayor a los 30 años de ambos sexos. Se infiere que en esta edad es factible obtener un grado informativo sobre estos temas más acabados. Si bien el número de muestra no ha sido cerrado, se estima que la coincidencia informativa constante podría inferirse entre los 50-100 casos. En este primer avance no es relevante la información obtenida de los visitantes, dado que la información que se requiere evaluar probablemente no sea accesible a estos. Sin embargo, la información que se consiga en el segundo ciclo tendrá otra importancia, dado que en este caso el visitante podrá evaluar en relación a los ajustes razonables que se realizaron a partir de la intervención gubernamental y que es susceptible de cotejar y valorar.

Las respuestas que se aborden reflejarán las áreas en las que se deberá trabajar para lograr una mayor eficiencia en la gestión, en relación a aquellas intervenciones planificadas en las que se observan planesproyectos-programas, y su grado de articulación entre ellas.

En el segundo ciclo de recolección e interpretación de datos se buscará tomar mayor conocimiento sobre esas intervenciones y sobre los resultados que emanan de las mismas. Un ejemplo de ello podría ser: si hablamos de infraestructura física del transporte, se deberán considerar subcategorías como terminales terrestres, marítimas, aéreas, pero también subcategorías que representen la comunicación en esas terminales y así constituirlas en una valoración que visibilice el grado de adaptación.

En todos los casos se deberá tomar en consideración el abordaje de la información a partir de las particularidades de cada discapacidad. Cada interrogante diseñado debería responderse a partir de las diferentes dimensiones o grupos que nuclean a los tipos de discapacidad, conformados de la siguiente manera: discapacidad sensorial, mental-intelectual, motriz ${ }^{16}$.

Por otra parte, es necesario reconocer algunas particularidades referidas a la discapacidad a partir del tiempo en el que se transita esa disfunción que, en la mayoría de los casos, está contemplada en la representación dimensional anteriormente mencionada.

\section{Conceptualización de los indicadores según las necesidades}

A continuación se desarrolló una conceptualización genérica de cada indicador presentado. La unidad de medida de los indicadores que se plantean emerge de los resultados obtenidos en el cuestionario, que configurará un resultado a partir del grado de intervención en materia de accesibilidad turística y la articulación entre las áreas de gobierno que se alcancen. Probablemente estos resultados se logren en un proceso de intervención diferencial entre los municipios, dado que de ello se desprende la configuración organizativa de cada municipio, y las líneas de intervenciones diferenciales.

16. A los fines de este trabajo se consideran como una dimensión única la discapacidad mental y la discapacidad intelectual. Para este grupo social, si bien se comprende las diferencias en cada patología de base, el abordaje de las diferentes acciones y/o servicios que se propongan en la comunidad visitada, requerirán de una adaptación similar para poderlas desarrollar -considerando siempre, las posibilidades de cada persona-. 


\section{Comunicación accesible}

La comunicación accesible es un intercambio o interacción entre una o más personas con un propósito determinado, a partir de un código que debe ser comprendido por los actores intervinientes. Esta comunicación adquiere mayor relevancia en determinadas discapacidades y no en otras. El modo de la comunicación se establecerá valorizando las habilidades desarrolladas en cada caso.

\section{Información accesible}

Para un municipio accesible es indispensable contar con una información exacta y adecuada que involucre en su acceso a la mayor cantidad posible de personas, incluyendo a aquellas que tienen algún tipo de deficiencia como visual, auditiva, sensorial y de movilidad. Para ello se deberá considerar el desarrollo de canales adecuados para su hallazgo, así como la comprensión que se realice de la información. Además, debe establecerse la actualización de sus datos, procurando mantener el formato inicial o, al menos, desarrollar cambios que no sean en su estructura. Por otra parte, la información deberá ser accesible a este colectivo social y deberá contener datos de su interés. Es decir, que los datos que se presenten y se comuniquen de manera accesible han de proporcionar toda la información concerniente a los diferentes servicios turísticos y no turísticos necesarios para desplegar las diferentes actividades de la vida cotidiana en plena libertad y autonomía. Este indicador se corresponde con los interrogantes: ¿Se comunica de manera accesible la información turística? ¿Existe señalización adaptada en el tema de discapacidad en el espacio público?

\section{Alojamiento turístico}

Corresponde a la acción de hospedar al visitante. En referencia a la discapacidad, es un factor esencial en la toma de conocimiento sobre los servicios que son posibles de brindar al huésped. Por otra parte, el obtener un registro actualizado, categorizado y accesible es de relevancia para su promoción e información. Este indicador se corresponde con el interrogante: ¿Existe un registro oficial sobre alojamientos turísticos que brindan los servicios accesibles en el destino turístico?

\section{Agencias y operadores turísticos}

Corresponde a las organizaciones privadas con fines de lucro. La información sobre los productos y servicios accesibles constituye uno de los elementos del sistema turístico fundamentales para insertarse en el mercado turístico. Este indicador se corresponde con el interrogante: ¿Existe un registro oficial sobre agentes de viajes y de los operadores turísticos que tengan información sobre la accesibilidad de los servicios en los destinos turísticos?

\section{Programa de desarrollo}

Se entiende como las diferentes políticas públicas relacionadas con la accesibilidad turística que se llevan a cabo en el municipio en las áreas vinculadas con el turismo, ya sea de manera directa o infiriendo en la misma. Este indicador se corresponde con el interrogante: ¿Se desarrollan políticas de accesibilidad en el municipio? 


\section{Infraestructura urbana}

Corresponde a la intervención humana que configura el soporte necesario para desarrollar diferentes actividades inclusivas en la ciudad. Este indicador se corresponde con el interrogante: ¿La infraestructura urbana del municipio es accesible?

\section{Infraestructura fija de transporte}

Se define como la intervención humana desarrollada principalmente a partir de la obra pública, relacionada con el transporte. Se presume la relevancia del automóvil y el transporte público como las principales modalidades. Este indicador se corresponde con el interrogante: ¿La infraestructura fija de transporte del municipio es accesible?

\section{Actividades}

Representan las acciones del ocio y turismo desarrolladas por el visitante y los habitantes de la comunidad, considerando el grado de accesibilidad. Este indicador se corresponde con el interrogante: ¿Existen actividades de ocio y turismo adaptadas? En la primera etapa evaluativa se intentará reconocer a partir de las políticas públicas existentes en el territorio, qué intervenciones gubernamentales alientan las actividades inclusivas.

\section{Capacitación}

Son las diferentes acciones desarrolladas por el sector público y/o privado en relación a la discapacidad y el turismo, con el propósito de promover el conocimiento y brindar un servicio acorde a las diferentes necesidades. Este indicador se corresponde con el interrogante: ¿El municipio capacita al personal sobre temas de capacidad y accesibilidad en el sector turístico?

A este tipo de revisión se deberán incorporar los diferentes grupos valorativos que aportan información, como son los visitantes-turistas, la comunidad local y el agente gubernamental. Esta demanda intenta construir resultados que, en suma, tiendan a una mayor "objetividad" pero sin dejar de observar su individualidad, para así establecer otra capacidad analítica, en la que se postulen interpretaciones que configuren un diagnóstico concreto de la realidad situacional a partir de cada valoración. Se presume que la mirada de los "agentes evaluadores"17 podría no coincidir con el resto. No es lo mismo obtener resultados de un interrogante respondido por un área gubernamental, que sobre la base del mismo interrogante respondiera la comunidad local o visitante, principalmente por los roles que cada uno cumple en esta interacción.

17. Agentes evaluadores, informativos o grupos valorativos: a los fines de este trabajo se denomina así al conjunto de personas que integran circunstancialmente un rol diferencial entre sí, que proporcionan información perceptiva sesgada a partir de una mirada subjetiva, de aspectos valorativos. Esta valoración se encuentra vinculada a la interacción territorial desarrollada según el rol y experiencia de cada persona. Ejemplo: el visitante-comunidad-funcionario. 


\begin{tabular}{|c|c|c|c|c|c|}
\hline \multirow[b]{2}{*}{ Dimensiones } & \multirow{2}{*}{$\begin{array}{l}\text { Indicadores } \\
\text { según las } \\
\text { necesidades }\end{array}$} & \multicolumn{3}{|c|}{ Valoración } & \multirow[b]{2}{*}{ Evidencia } \\
\hline & & $\begin{array}{c}\text { Agente } \\
\text { gubernamental }\end{array}$ & Comunidad local & Turista & \\
\hline \multirow[t]{9}{*}{$\begin{array}{l}\text { Discapacidad } \\
\text { sensorial }\end{array}$} & $\begin{array}{l}\text { Comunicación } \\
\text { accesible }\end{array}$ & & & & \\
\hline & $\begin{array}{l}\text { Información } \\
\text { accesible }\end{array}$ & & & & \\
\hline & $\begin{array}{l}\text { Alojamientos } \\
\text { turísticos }\end{array}$ & & & & \\
\hline & $\begin{array}{l}\text { Agencias de viajes } \\
\text { y Operadores } \\
\text { turísticos }\end{array}$ & & & & \\
\hline & $\begin{array}{l}\text { Programa de } \\
\text { desarrollo }\end{array}$ & & & & \\
\hline & $\begin{array}{l}\text { Infraestructura } \\
\text { urbana }\end{array}$ & & & & \\
\hline & $\begin{array}{l}\text { Infraestructura fija } \\
\text { de transporte }\end{array}$ & & & & \\
\hline & Actividades & & & & \\
\hline & Capacitación & & & & \\
\hline
\end{tabular}

Fuente: elaboración propia.

Así mismo, una vez obtenido el dato, es necesario indagar sobre la "evidencia", para convalidar la respuesta obtenida y así poder configurar los resultados de esta primera etapa evaluativa. Dicha evidencia tiene un rol indispensable en la mayoría de los interrogantes propuestos. El administrar datos concretos como documentación fehaciente de lo consultado o la verificación de la "realidad" respondida, reafirma la objetividad y acota la brecha interpretativa de los resultados obtenidos. Por ello, la obtención de la documentación será una condición de alta valoración en el momento de recolectar los datos. En algunos de los casos son respuestas irrefutables al considerar como "real, verdadera y certera" aquella información obtenida, y por ello la evidencia no será relevante, por ejemplo, sobre la existencia o no de rampas de accesibilidad física.

Una vez revisados los datos se procesará la información obtenida, sintetizando sus respuestas en una representación de tres colores: verde-amarillo-rojo. Estos colores tienen como finalidad trasmitir el grado de desarrollo de las políticas públicas en materia de accesibilidad turística en el municipio, considerando la representación del color con el porcentaje alcanzado en la sumatoria de los indicadores propuestos. La cantidad de indicadores y subindicadores a desarrollar en la revisión quedará sujeta a la disponibilidad de recursos materiales y humanos para revisar la información. Cada uno de los indicadores tendrá un valor entre 0 a 2 puntos. El cero representará la falta de dicha política pública, mientras que el valor 1 estipulará la concreción de dicha intervención y/o articulación de la política pública. El valor 2 se le asignará a la representación planteada en el 1 pero a los casos en que el indicador constituya para la dimensión valorada un nivel concreto para lograr su accesibilidad -la valoración máxima en la relación valorativa de la accesibilidad física, en el caso de la dimensión sobre la discapacidad motriz-. Otro ejemplo posible es que el indicador relacionado 
con la comunicación accesible, en la dimensión mental, tendrá una puntuación de 2. Si bien este mismo indicador, en el caso de la dimensión relacionada con la discapacidad física, obtendrá una puntuación de 1.

Los resultados obtenidos, se proyectarán en una escala de colores, representados en la figura 5 , que constituirán el porcentaje valorado, a saber:

- Color verde: como la representación máxima en el desarrollo de dichas políticas. Se obtiene mediante una gestión consecuente de una plena adaptación de los servicios, actividades y territorio en su relación con el diseño inclusivo, en donde las políticas públicas desplegadas establecen una conformidad plena a la totalidad de los actores que evalúan la gestión. Y las estrategias de actuación son esenciales y conforme a las necesidades tanto de su población como de sus visitantes. Recomendación: en este caso estaríamos indicando que no existe una demanda específica no resuelta de los temas seleccionados. Se le asignará un porcentaje de la gestión en un intervalo entre el 80 y el 100 por ciento.

Obtener como resultado esta valoración implicaría el desafío de mantener las acciones necesarias para que perdure dicha situación.

- Color amarillo: sugiere un grado de accesibilidad turística en el que aún se denotan algunas cuestiones de déficit en la materia y/o en las áreas gubernamentales en las que se debería gestionar. Recomendación: en este contexto se plantea un doble camino en el que se deberá trabajar para mantener los niveles alcanzados, así como trabajar en aquellas cuestiones que se evidenciaron en el cuestionario y que se plantearon como no resueltas. En este caso se podría visibilizar diferente déficit de gestión o percepción de la misma, según la valoración de los agentes gubernamental-comunidad local-visitante. En el color amarillo se asigna un porcentaje de intervalo entre el 40 y el 60 por ciento. Allí se destaca un valor relativo a las intervenciones gubernamentales realizadas, en tanto un descuento valorativo a las acciones no resueltas.

- Color rojo: demuestra un gran déficit en las políticas públicas y en las estrategias de actuación gubernamental que tienen el propósito de establecer un territorio inclusivo. Recomendación: se plantea la necesidad urgente de poner las políticas públicas al servicio de sus habitantes, así como preparar un territorio turístico que sea accesible también a sus visitantes. En este caso se observa un porcentaje en intervalo que va del 0 al $30 \%$. Allí se plantean grandes desafíos en la gestión para establecer acciones acordes a las necesidades reales para lograr la accesibilidad turística.

Figura 5. Semáforo de accesibilidad turística

ACCESIBLE

INTERVALO DE $80 \%$ A $100 \%$.

ALGUNAS ADAPTACIONES

INTERVALO DE $40 \%$ A $60 \%$.

NO ACCESIBLE

INTERVALO DE $0 \%$ A $30 \%$.

Fuente: elaboración propia. 


\section{Síntesis de los resultados preliminares}

El abordaje al conocimiento en referencia al proyecto de investigación desplegado propone un avance metodológico sobre la evaluación de la calidad en la gestión municipal en referencia a la accesibilidad turística. Para ello se diseñó un cuestionario que aportó la información básica para la construcción de indicadores que establecieron el grado de accesibilidad turística alcanzada, a partir de las acciones gubernamentales. La aplicación de manera experimental de parte de la metodología presentada en el proyecto de investigación, ha sido respondida por las autoridades de Puan (directora de turismo: Cora Biondini) y Tornquist (secretaria de turismo: Georgina Siebenhar). Los resultados obtenidos en el momento de la presentación de este artículo contemplan la situación en dicha materia analizada -accesibilidad turística-, según los datos recolectados de una sola fuente. En consecuencia con el propósito del trabajo de investigación, será conveniente continuar con el análisis de los resultados provenientes del resto de los agentes evaluadores o informativos y de las organizaciones gubernamentales de las localidades de Adolfo Alsina, Villarino y Guaminí, comprendidas en el corredor turístico.

A partir de este abordaje, se observa de manera preliminar la siguiente interpretación. En el caso de la localidad de Puan, observamos que la accesibilidad turística se encuentra desarrollada en algunas de sus acciones gubernamentales. En relación a las obras de infraestructura urbana municipal, se visualiza el reconocimiento de una necesidad explícita para la sociedad en su conjunto, respecto a acciones que faciliten el libre acceso. En razón de ello, se desarrollaron obras referidas a la accesibilidad física en un gran número de calles, terminal de ómnibus y oficina de turismo. También se han establecido acciones en referencia a la accesibilidad sensorial en el museo Ignacio Balvidares y la accesibilidad física en el sector de la piscina municipal. Vale decir que la infraestructura urbana del municipio es parcialmente accesible, dado a que aún restan obras de accesibilidad física en algunos de sus circuitos turísticos como así también la accesibilidad a partir de otras disfunciones. Por otra parte, se evalúa como deseable que los esfuerzos sean extensivos al resto de las deficiencias.

En este municipio han observado la necesidad de trabajar en una ordenanza municipal que acompañe la gestión pública sobre temas diversos relacionados con la discapacidad y el turismo y esta se encuentra en su etapa de elaboración. Se ha planteado la necesidad de acciones, por ejemplo: en el desarrollo de revisiones o algún tipo de registro en alojamientos turísticos, accesibilidad física, restauración -aunque existe un registro de restauración, no está aún sistematizado-.

La capacitación del personal del organismo público es un eje que el distrito considera relevante establecer. En tanto si bien se desarrolla capacitación técnica de guiado, se visualiza como necesario continuar con el perfeccionamiento en la temática en el sector público y privado en materia de discapacidad y turismo.

La comunicación virtual sobre información turística referida a Puan presenta grandes avances al respecto, principalmente en la calidad informativa sobre los contenidos y actividades asociadas al turismo en su sitio web oficial, mientras que aún no se ha desarrollado la accesibilidad. Los foletos, como parte de la comunicación establecida por el municipio turístico, presentan información relevante en materia turística. Se observa como necesaria la incorporación de datos referidos a servicios turísticos y no turísticos accesibles, adaptados en su presentación. En los puntos informativos del organismo de turismo, prevén contar con algún recurso informativo sobre todo en relación a servicios en los que se puede acceder con movilidad reducida. La señalética en el espacio público del lugar se encuentra escasamente desarrollada, no siendo aún adaptada. 
Se observa como una gran oportunidad el desarrollo de una agencia y operadores turísticos en la localidad, incorporando la accesibilidad en los servicios turísticos, así como en la forma en que los ofrecen. Actualmente no se encuentran desarrollados estos servicios en el municipio.

El registro sobre los visitantes, se encuentra gestionado, en tanto no se discrimina en relación a este colectivo social, este podría ser una política conducente en materia de calidad turística, por plantear la posibilidad de diferentes características de abordaje analítico.

El transporte público sigue siendo una asignatura pendiente, tanto en el interior del territorio como en la interconexión de las localidades que integran el corredor turístico.

Se pudo tomar conocimiento de manera genérica sobre las acciones congruentes a la discapacidad, principalmente en el acompañamiento económico y social de este colectivo.

Es de destacar que en el municipio de Puan se observa un gran interés en desarrollar políticas públicas inclusivas y también se percibe como positivo el trabajo articulado del área de turismo, con varios departamentos de la estructura gubernamental municipal y provincial, principalmente.

En el caso de la localidad de Tornquist, encontramos situaciones similares a las enunciadas en la localidad anteriormente analizada, en algunos de los lineamientos planteados.

La comunicación sobre información turística del municipio, como en los sitios webs, folletos y señalética, no cuenta con la adecuación en materia de accesibilidad, a excepción del sendero y cerros del Parque Provincial Ernesto Tornquist, en el que se destaca el grado de dificultad; y de los alojamientos habilitados en los que se cuenta con la información de su tipo de accesibilidad. Así mismo se ha observado en las rutas de acceso al municipio una enorme cantidad de carteleras de servicios, principalmente de alojamientos privados, que son un impedimento a la claridad informativa que se pretende establecer desde los objetivos propuestos por el organismo encargado de la información vial -Dirección Nacional de Vialidad-. Se trata de elementos que imposibilitan o estorban la visualización paisajística y se observa también que la seguridad vial se encuentra comprometida.

En materia de infraestructura urbana, en el municipio de Tornquist existen cuatro oficinas de informes turísticos en: Tornquist, Villa Ventana, Sierra de la Ventana y Saldungaray, si bien no todas presentan accesibilidad física.

La información referida a restauración y la accesibilidad de los mismos, aún no cuenta con un registro sistematizado ni con estadísticas de visitantes con algún tipo de discapacidad.

Se ha tomado conocimiento sobre la existencia de una figura gubernamental denominada "agente turístico" que, entre otras funciones, durante el proceso de habilitación del alojamiento turístico, revisa el grado de accesibilidad del mismo. En dichas revisiones se cuenta con información, pero solo focalizada en materia de accesibilidad física, en tanto es un dato más que contribuye a la construcción del registro.

En relación a algunas actividades turísticas accesibles desarrolladas en el territorio, se informó de que existe accesibilidad visual en los siguientes puntos: los Cerros Ceferino y Calvario. Así también, las plazas de Er- 
nesto Tornquist e Independencia, en las que se despliegan obras del Arq. Ing. Francisco Salamone, pueden ser transitadas por personas usuarias de sillas de ruedas. El Parque Lineal también es accesible para personas invidentes y usuarias de silla de ruedas.

Como dato representativo surgido de la entrevista desarrollada en campo con personal de la oficina de turismo de Tornsquist sobre la evolución de la situación del municipio en materia de accesibilidad emergente, destacar la confección de un folleto en braille en el año 2014. Esta ha sido una gestión desarticulada de la gestión municipal, en la que ha intervenido la Unidad Penal 19, de la localidad de Saavedra (Internos Pabellón 12). Solo unas 100 unidades han sido distribuidas en las oficinas de informes turísticos.

No se pudo obtener información sobre la existencia de acciones políticas y de gestión en materia de accesibilidad.

Finalmente cabe destacar la labor desarrollada por el equipo de trabajo que nuclea al corredor turístico, así como sus múltiples acciones y esfuerzos para promocionar el territorio y abordar cuestiones coyunturales y de largo plazo, estableciendo una sinergia entre sus integrantes. Como acto en el que se refleja la asociatividad territorial y personal se destaca la conformación de un proyecto presentado a la Nación, al ente máximo en la gestión del turismo, en el que se destacan las acciones regionales por sobre las individualidades, representando su esfuerzo.

\section{Conclusiones}

El abordaje al conocimiento en referencia al proyecto de investigación desplegado, propone establecer una metodología evaluativa de la calidad en la gestión municipal determinada en dos ciclos de abordaje, en relación a las necesidades de las personas con discapacidad y aquellas que presentan algún tipo de deficiencia que mediante los ajustes razonables puedan lograr la plena participación en la sociedad. De acuerdo a los avances preliminares elaborados, el modelo de evaluación de la calidad en la gestión ambiental municipal sobre este eje estudiado, entre otros, presenta algunas conclusiones a priori.

- Se establece de manera preliminar una metodología de abordaje de la situación del municipio en relación a la accesibilidad turística, puntualizando en las necesidades de las personas con necesidades de accesibilidad de la comunidad local y del visitante.

- Se observa como desafío hacia el futuro, que la coordinación entre las áreas de trabajo de la estructura municipal es fundamental para lograr una gestión integral y sistémica que resuelva las necesidades planteadas en el objetivo.

- El interrogante sobre si existen políticas de accesibilidad en el municipio, es muy genérico, posiblemente se necesite establecer por parte del interlocutor una especificidad en el tema para poder obtener datos interrelacionados a la construcción de una gestión integral para enriquecer y hacer más confiable el dato. 
- Los datos gubernamentales hasta al momento revisados se deberán considerar como datos que podrían estar impregnados de intencionalidad. Se debe considerar la necesidad de un abordaje, a partir del resto de los agentes evaluadores enunciados, que configure un resultado más objetivo de la situación del territorio, a pesar de que algunas respuestas sean especificas de la gestión. En el caso de cuestiones sociales como la discapacidad, son datos que podrían estar en conocimiento de la población local, principalmente.

- La obtención de la evidencia que se promueve alcanzar, si bien en algunos casos puede presentar dificultad para adquirirla, es necesaria para conocer sobre lo consultado y como posible nueva capa analítica que indague para lograr los resultados informativos deseados.

- Se visualizan algunos avances relevantes en la gestión en materia de accesibilidad turística de las localidades presentadas analíticamente, aunque estos esfuerzos se encuentran desaprovechados, dejando invalidada una gran potencialidad, sobre todo en algún déficit en particular, dado que los esfuerzos de adaptación para incluir a este colectivo deben proponerse para toda su cadena de servicios -origendestino-. En el caso de algunas discapacidades, es necesario que todos los servicios estén adaptados a sus necesidades para poder lograr su autonomía. De todas maneras es muy valiosa la decisión manifiesta, adquirida por la gestión municipal, para alcanzar el propósito de la accesibilidad. 
Referencias bibliográficas

Argentina. Ley Nacional de turismo accesible No 25643. Turismo accesible y p/personas discapacitadas. Boletín Oficial, 12 de septiembre de 2002, núm. 29982, p. 2 (en línea). <http://servicios.infoleg.gob.ar/infoleglnternet/ anexos/75000-79999/77719/norma.htm>, acceso 20 de marzo de 2019.

Bertalanffy, L. V. (1968): General systems Theory. Foundations, development, applications. New York: George Braziller.

Blanco, I. et al. (2016): El municipalisme del bé comú. Barcelona: Icària.

Brugué, J. et al. (1998): "Las políticas públicas locales: agendas complejas roles estratégicos y estilo relacional”, en Brugué, J. y Gomà, R. (coords.): Gobiernos locales y políticas públicas. Barcelona: Ariel.

Comisión Económica para América Latina y el Caribe-CEPAL (2017): Discapacidad y políticas públicas: avances y desafíos institucionales en América Latina. Seminario Internacional "Protección social e institucionalidad: desafíos presentes y futuros para la inclusión en América Latina y el Caribe". Santiago de Chile, 28 y 29 de agosto de 2017 (en línea). <https://www.cepal.org/sites/default/files/presentations/presentacion_heidi_ullmann_0. pdf>, acceso 20 de marzo de 2019.

Comisión Nacional Asesora para la Integración de Personas Discapacitadas (2003): Plan Nacional de Accesibilidad. Buenos Aires: Consejo Nacional de Coordinación de Políticas Sociales. Presidencia de la Nación.

Cravacuore, D. (comp.) (2015): “El agotamiento de un modelo". Revista Digital RIL, 1: 4-7.

Galafassi, G. (2006): "Ecological Crisis, Development and Capital Contradictions in Latin America”, en Harris, R. y Nef, J (eds.): Capital, Power, and Inequality in Latin America. Boulder (USA): Rowman \& Littlefield Publishers.

Gallopin, G. (2006): Los indicadores de desarrollo sostenible: aspectos conceptuales y metodológicos. Ponencia realizada para el Seminario de expertos sobre indicadores de sostenibilidad en la formulación y seguimiento de políticas. Chile.

Ivars Baidal, J. (2001): "Planificación y gestión del desarrollo turístico sostenible: propuestas para la creación de un sistema de indicadores" (en linea). <https://rua.ua.es/dspace/bitstream/10045/20506/1/Planificacion_gestion_sostenible_desarrollo_turistico_sostenible.pdf>, acceso 3 de marzo de 2018.

Mazza, C. (2018): “Turismo y discapacidad. ¿Un Marco regulatorio con inclusión?”. Revista Divulgatio, 6 (en línea). <http://revistadivulgatio.web.unq.edu.ar/?page_id=80\&num-ejemplar=6>, acceso 3 de abril de 2019.

Núñez, A. et al. (2011): "Reflexiones sobre falacias conceptuales y acciones concomitantes en políticas urbanas y sociales en Argentina". Revista Theomai. Primer semestre, 23: 193-204 (en línea) <http://revista-theomai. unq.edu.ar/NUMERO\%2023/12_Nu\%C3\%B1ez-Roze\%20pa\%20pdf_193-204.pdf>, acceso 10 de marzo de 2019.

Organización de Naciones Unidas (2006): Convención sobre los derechos de las personas con discapacidad (en línea). <http://www.un.org/spanish/disabilities/default.asp?id=497>, acceso 3 de marzo de 2017.

Organización Mundial de la Salud (2011): Informe de la OMS sobre personas con discapacidad (en línea). <http:// apps.who.int/iris/bitstream/10665/70672/1/WHO_NMH_VIP_11.03_spa.pdf>, acceso el 3 de marzo de 2017.

Organización Mundial del Turismo (2016): Turismo accesible para todos: una oportunidad a nuestro alcance. Madrid: OMT. 
Organización Mundial del Turismo (2014): Recomendaciones de la OMT por un turismo accesible para todos. Madrid: OMT (en línea). <http://cf.cdn.unwto.org/sites/all/files/docpdf/accesibilityes.pdf>, acceso 3 de marzo de 2017.

Organización Mundial del Turismo (2000): Taller de indicadores de sostenibilidad en turismo para los países de sudamérica. Informe final. Villa Gesell, Argentina, Madrid.

Organización Mundial del Turismo (1999): Código ético mundial para el turismo. Madrid: OMT.

Organización Mundial del Turismo (1997): Lo que todo gestor turístico debe saber: guía práctica para el desarrollo y uso de indicadores de turismo sostenible. Madrid, OMT.

Organización Mundial del Turismo, PNUMA (2005): Por un turismo mas sostenible: Guía para responsables políticos. Madrid: OMT, PNUMA.

Puga, D. (2005): "La dependencia de las personas con discapacidad: Entre lo sanitario y lo social, entre lo privado y lo público". Revista Española de Salud pública, 3: 79 (en línea). <http://scielo.isciii.es/scielo.php?pid=S1135$57272005000300001 \&$ script=sci_arttext\&tlng=e>acceso 3 de diciembre de 2016.

Reboratti, C. (2000): “Ambiente y sociedad. Conceptos y relaciones”. Mundo agrario, 1 (1): 1.

Romero, J. (2011): “¿Territorios inteligentes, sostenibles e inclusivos? Enseñanzas de la experiencia española”. Revista Hábitat y Sociedad, 2: 13-32 (en línea). <https://docs.google.com/viewerng/viewer?url=idus.us.es/ xmlui/bitstream/handle/11441/22145/file_1.pdf?sequence\%3D1\&isAllowed=y>, acceso 16 de abril de 2019.

Sánchez, D. (2011): "Indicadores turísticos en la Argentina. Una primera aproximación. Investigaciones turísticas". Universidad de Alicante. Instituto Universitario de Investigaciones Turísticas, 2: 29-65.

Sancho, A. et al. (2007): "Comparativa de indicadores de sostenibilidad para destinos desarrollados, en desarrollo y con poblaciones vulnerables". Annals of Tourism Research en español, 1 (9): 150-177.

Subirats, J. (2010): "Si la respuesta es la gobernanza, ¿cuál es la pregunta?: factores de cambio en la política y en las políticas”. Ekononomiaz: Revista Vasca de Economía, 74: 16-35. 